\title{
ECOSYSTEM STRATEGY IN TECHNOLOGY LICENSING
}

https://doi.org/10.17863/CAM.10954

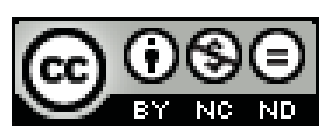

Mingjin Guo (CTM, University of Cambridge) * Xianwei Shi (CIM, University of Cambridge) Frank Tietze (CTM, University of Cambridge)

* Please contact the corresponding author for feedback: mg720@cam.ac.uk

This paper has been accepted to the Academy of Management 2017 (Atlanta, US) and also been presented at the International Doctoral Student Conference 2017 (Zhejiang University, China) 


\title{
Ecosystem Strategy in Technology Licensing
}

\author{
Mingjin Guo, Xianwei Shi, Frank Tietze
}

\begin{abstract}
The last few decades have witnessed a significant increase in licensing. Firms usually license in or out patents for technology acquisition or exploitation and other strategic purposes. Although literature has discussed the optimal licensing strategy for patent holders, the value of the technology is not completely exploited due to a few reasons. One of the challenges results from the presence of innovation ecosystem, where complementors have great impact on both licensors' and licensees' product performance. In this paper we focus on licensors' ecosystem strategy, i.e. engaging complementors, in their licensing scenarios. By mathematical proof in an extended model based on the literature, we find that involving complementors is profitable for licensors, but involving too many would cause decrease in the profitability. We also conclude that the relative position of the licensor in the licensing competition (i.e. relative numbers of licensees) is the key to determine its ecosystem strategy. When the licensor licenses less aggressively than its competitors and has small transaction cost with complementors, involving complementors is a supportive strategy to its existing licensing strategy. However when the licensor is licensing more than others, engaging complementors would be unfavourable.
\end{abstract}

Keywords: Innovation Ecosystem; Ecosystem Strategy; Licensing; Market for Technology 


\section{INTRODUCTION}

Licensing has been used extensively in the industry as a means of technology acquisition or exploitation for many years (Kamiyama et al. 2006). The last decades have witnessed a dramatically growing trend in licensing especially in technology-intensive industries, such as semi-conductor and pharmaceutical industries (Grindley \& Teece 1997; Allarakhia \& Walsh 2011). Firms with innovations even license their patented technologies out to potential competitors. Traditional explanation for this is that firms lack the capability to commercialize and exploit their technologies compared with their licensees (Arora \& Ceccagnoli 2006), such as most start-ups with only patents. However, evidence from large firms' aggressive licensing behaviour indicated that licensing has been used strategically even though these firms possess the capabilities to utilise their technologies (Rivette \& Kline 2000). In this scenario, firms license for various strategic purposes: to increase demand, to deter entry or to choose competitors (Gallini 1984; Shepard 1987; Rockett 1990). Our paper is related more to the latter scenario, where licensors may still have easier access to complementary assets than their licensees.

Numerous studies have discussed the optimal licensing strategy for patent holders (Katz \& Shapiro 1986; Arora \& Fosfuri 2003). Nowadays, the new task faced by licensors is how to maximize value exploited from their technologies in the existing licensing network. There are several reasons for insufficient rent exploitation, including transaction cost of licensing contracts (Caves et al. 1983), asymmetric information (Gallini \& Wright 1990), and weak intellectual property rights protection (Gallini 1992).

In addition to these, the presence of innovation ecosystems nowadays and high technological interdependence between different industrial players (Adner \& Kapoor 2010) also pose a challenge on licensees' rent generation of the technology and further on licensors' profitability. The concept of innovation ecosystem has received increasing attention in recent years (Adner 2006; Adner 2016; Kapoor \& Lee 2013). It highlights the interaction between firms that are technologically connected and especially the strategic importance of complementors, which we will illustrate later in the theory section (Adner \& Kapoor 2010). Adner and Kapoor (2010) argued that complementors in an innovation ecosystem impact the focal firm's performance in creating value of their products. Therefore, in a licensing contract, one can see that even with higher capability to commercialize the technology than the licensor, the licensee still risk the inefficiency of capturing value from the licensed technology. This may result from failing to identify potential complementors or acquiring additional complementary technologies. The same logic applies to the licensor that is also involved in the product market. In summary, the licensor should pay attention to the ecosystem strategy in its licensing activity to deal with this challenge.

Hence, this paper mainly focuses on the ecosystem strategy for licensors if they wish to mitigate the ecosystem challenge and maximise the rent of their licensing contracts. Here ecosystem strategy mainly refers to engaging complementors strategically. The paper 
discusses the following issues for the licensor: 1) whether introducing complementors into its licensing framework brings more profit to itself; 2) when to engage and how many (roughly) complementors to engage, and how asymmetry of the licensing market influence this. The study on the second issue leads to further discussion on when ecosystem strategy acts as a complementary strategy to firm's licensing strategy and when as a conflicting strategy. We examine our propositions using an extended analytical model based on Arora and Fosfuri's (2003).

The paper is structured as follows: theory of market for technology and innovation ecosystem that this paper is based on will come first. Then the method part mainly presents the analytical model, including its conceptual background and the mathematical part followed by the solution. The findings\&discussion part constitutes the core of the paper, which will present our propositions followed by corresponding proof and discussion. Finally, we bring our findings together and conclude the paper with limitations and future work.

\section{THEORY}

\section{Theory on technology licensing}

Existing literature on firms' licensing mainly focus on two aspects: incentives for licensing behavior and licensing strategy. In terms of motivation, companies license patents mainly for technology acquisition (license in) or exploitation (license out) (Lichtenthaler 2005). It is also believed that license strategy is an effective way for firms to access complementary assets, which are crucial for them to appropriate value from their innovation (Arora \& Ceccagnoli 2006; Teece 1986). Especially for firms with large manufacturing capability but fewer technologies, they will license in technologies actively (Teece 1998). In addition, existing literature has also tried to discuss the incentives of licensing from the economic perspective. Before we talk about research specifically on licensing, literature has argued that delegation or franchise helps retailers to exploit their surplus in a vertical market and deter entry (Vickers 1985; Bonanno \& Vickers 1988; Hadfield 1991; Gallini 1984). Researchers also argued that licensors treat licensing as a strategy to enhance demand and therefore maximize profits from the proprietary product (Shepard 1987). Rockett (1990) showed that licensing is a way of selecting competitors after the patent expires (Rockett 1990).

Regarding the discussion on licensing strategy, a number of studies have tried to study the influence of some determinants on firms' licensing propensity. Pitkethly mainly discussed different licensing strategies with different levels of strategic appropriability, legal appropriability and access to complementary assets. Arora and Ceccagnoli (2006) investigated the relationship between the effectiveness of patent protection and firms' propensity of licensing. They found that when firms possess specialised complementary assets for technology commercialisation, the increase of the effectiveness of patent protection will result in the increase of patenting propensity and the drop in license propensity; when firms lack specialised complementary assets, the increase of this determinant will lead to the increase of licensing propensity. Therefore, the effectiveness of IP protection was proved to be a key determinant of IP strategy (patenting or licensing), with the ownership of specialised complementary assets having a mediating effect (Arora \& Ceccagnoli 2006). 
Motohashi (2008) further illustrated the influence of firm size on license strategy decisions using empirical data from Japanese companies. A few researchers focused on the characteristics of knowledge and technology and discussed their impact on licensing behavior. Alexy et al. mainly discussed the impact of knowledge distribution and technological environment (Alexy et al. 2009). Allarakhia and Walsh focused on the features of knowledge such as complementarity and substitutability (Allarakhia \& Walsh 2011).

In addition to the study on determinants in the management literature, economic research mainly focused on the optimal licensing strategy. Gallini and Wright (1990) discussed the optimal licensing contract design under asymmetric information scenario between licensors and licensees (Gallini \& Wright 1990). Katz and Shapiro (1986) showed the licensing behavior for a monopolist innovator that is not engaged in the product competition (Katz \& Shapiro 1986).

This paper is based on the theory of market for technology that was proposed by Arora et al (2001). They applied the term 'market' in the economic area that usually refers to the product market, into the competition where technology is the 'product'. The theory of market for technology contributes to the economics of intellectual property. For most of the time, technology itself cannot be flexibly transferred in the market, while the property rights patents - enable firms to transfer their technologies and exploit the rent through licensing or selling. After the concept 'market for technology' was built, one can study the licensing activity through a multistage market structure, including the market for technology and the common market for product. In addition, one can discuss a variety of issues such as transaction cost, rent of innovation etc. in the technology market. Arora et al. (2001) also suggested that the presence of market for technology expands the firms' strategic space. This includes a variety of strategic choices within the licensing scope, such as licensing in or out, the extent of licensing etc., and other technology acquisition and exploitation strategies (Arora et al. 2001).

With this conceptual foundation Arora and Fosfuri (2003) further proposed an analytical model that explained innovators' licensing strategy in a technology market. They regarded licensing as 'a credible commitment to expand production by transferring the output decision to the licensees'. Their model relaxed the assumption of a single monopolist technology holder in the licensing market and discussed the scenario where more than one patent holder exists. Through mathematical solution, the model further showed why firms license their technologies to potential competitors. They argued that the degree of competition in the product market is one of the keys. Also, they showed that the optimal number of licensees for a technology holder is influenced by the competition in the technology market, transaction cost and the degree of product differentiation (Arora \& Fosfuri 2003).

In this paper, we base on the model proposed by Arora and Fosfuri (2003) and propose our extended model that involves complementors in the innovation ecosystem. Note that our focus is not on the licensing strategy with complementors involved, but rather the ecosystem strategy (engaging complementors) under this licensing framework. This attempt is important because for a product manufacturer (licensee), only a single contract for a single technology does not fit the reality, which was also noted as limitation of their model in Arora and Fosfuri's paper (2003). A single product usually involves different technologies and there exists great 
interdependence among these technologies (Adner \& Kapoor 2010). Therefore, as licensors, the technology holders can seek new strategic choices in their innovation ecosystem to exploit the profit from licensing the technology.

\section{Innovation Ecosystem}

Inspired from ecological research, Moore first introduced business ecosystem as "an economic community supported by a foundation of interacting organizations and individuals" (Moore 1993, 1996, 2004). The ecosystem thinking, describing business networks where interconnected and interdependent organisations interact and engage with each other (lansiti \& Levien 2004a, 2004b; lansiti \& Richards 2006), has since then introduced into different domains, thereby forming different ecosystems addressing different issues, such as innovation ecosystems (Adner 2006; Adner \& Kapoor 2010) and entrepreneurial ecosystems (Cohen 2006; Nambisan \& Baron 2013).

The ecosystem we refer to in this paper stems from Adner's innovation ecosystem, which addresses the critical importance of complementors (Adner 2006) - a distinctive component beyond traditional dyadic relationships in supply chains or networks (Davis 2016), as illustrated in Figure 1. Adner argues that success of focal firms' innovation is contingent on the complements provided by complementors in the downstream due to technological interdependence (Adner 2012). Without the latter, focal firms' new offerings are likely to fail even with excellent ideas and implementation capabilities. In other words, focal firms' innovation can be utilised by customers to its full potential only when compliments are present and bundled (Adner 2006).

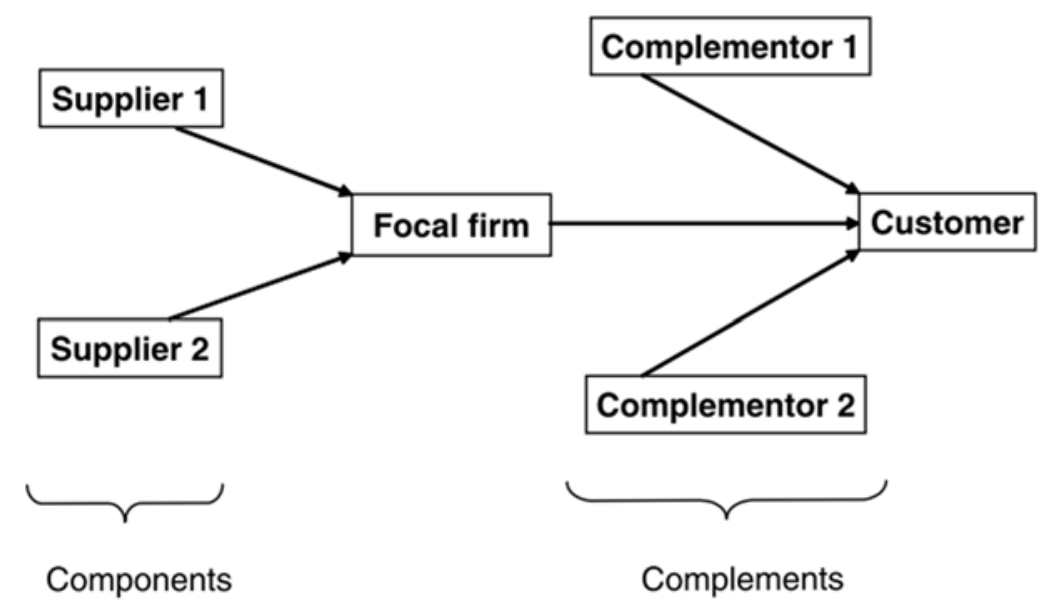

Figure 1. The innovation ecosystem schema (Adner \& Kapoor, 2010)

Empirical research based on global semiconductor lithography equipment industry reveals that the innovation bundles that integrate the complementors' innovations with their own products are of vital importance for focal firms to be successful in the market (Adner \& Kapoor 2010). They argue that "greater upstream innovation challenges in components enhance the benefits that accrue to technology leaders, while greater downstream innovation challenges in complements erode these benefit" (Adner \& Kapoor 2010). Based on their 
innovation ecosystem framework, further studies have revealed how alliances with complementors will affect focal firms' technological investment choices (Kapoor \& Lee 2013) and how the pace of technology substitution is contingent on the ecosystem challenges for new technologies and ecosystem extension for older ones (Adner \& Kapoor 2015).

\section{Ecosystem Strategies}

Though researchers still have not reached an agreement on what exactly ecosystem strategy is, the basic idea of implementing ecosystem strategies is to nurture an ecosystem if not existed and necessary. Rong and Shi (2014) has identified the nurturing patterns and processes where a set of partners coevolve along the process (Gawer \& Cusumano 2013; Rong \& Shi 2014). The co-evolutionary process, orchestrated by the ecosystem leaders, will grow the whole ecosystem from scratch and build up competitive advantages (Liu \& Rong 2015). Thomas and Autio also proposes some key dimensions to create an ecosystem such as manipulating shared vision/perception of ecosystem standards, and manipulating normative forces (Thomas \& Autio 2015; Autio \& Thomas 2016)

But is it actually beneficial for firms to implement ecosystem strategies? For focal firms, implementing an ecosystem strategy could be beneficial just as implementing a traditional strategy. Adner argues that, if traditional strategies are searching for building competitive advantages of the firms, ecosystem strategy is searching for the value co-creation alignment and then forming the innovation alignment of partners (Adner 2017). In so doing, the focal firm could increase the competitiveness of their ecosystem, which can further increase their own market share and profit (lansiti \& Levien 2004b).

In summary, although previous literatures have established models that explain the licensing strategies in the market for technology and the optimal scenarios to compete in the market for product, relatively less is known about how the technology holder could increase its profit in an innovation ecosystem context. The innovation ecosystem context is of relevance in that simple dyadic buyer-supplier relationships between technology holders and licensees in the previous model settings are replaced by triadic relationships (Davis 2016) between technology holders, complementary technology holders and licensees. Technology holders' technologies alone simply are not enough for downstream firms to ensure their success in the product market. Instead, they must be accompanied by complementors - in this paper, the complementary technology holders in the market for technology. This qualitative difference will change technology holders' strategic decisions under a variety of uncertainties, which we will quantify in our model.

Thus, we have laid down theoretical foundations for our modelling and illustrates the gap in this domain, which helps formulate our research question: 'How can licensors engage complementors in the innovation ecosystem as a complementary strategy with its existing licensing scenario?'

\section{METHOD}

\section{The conceptual framework}

Our conceptual framework is based on the scenario that Arora and Fosfuri (2003) describe. 
We however advance their scenario by employing complementors into the technology market as complementary patent providers. The framework is shown in Figure 2.

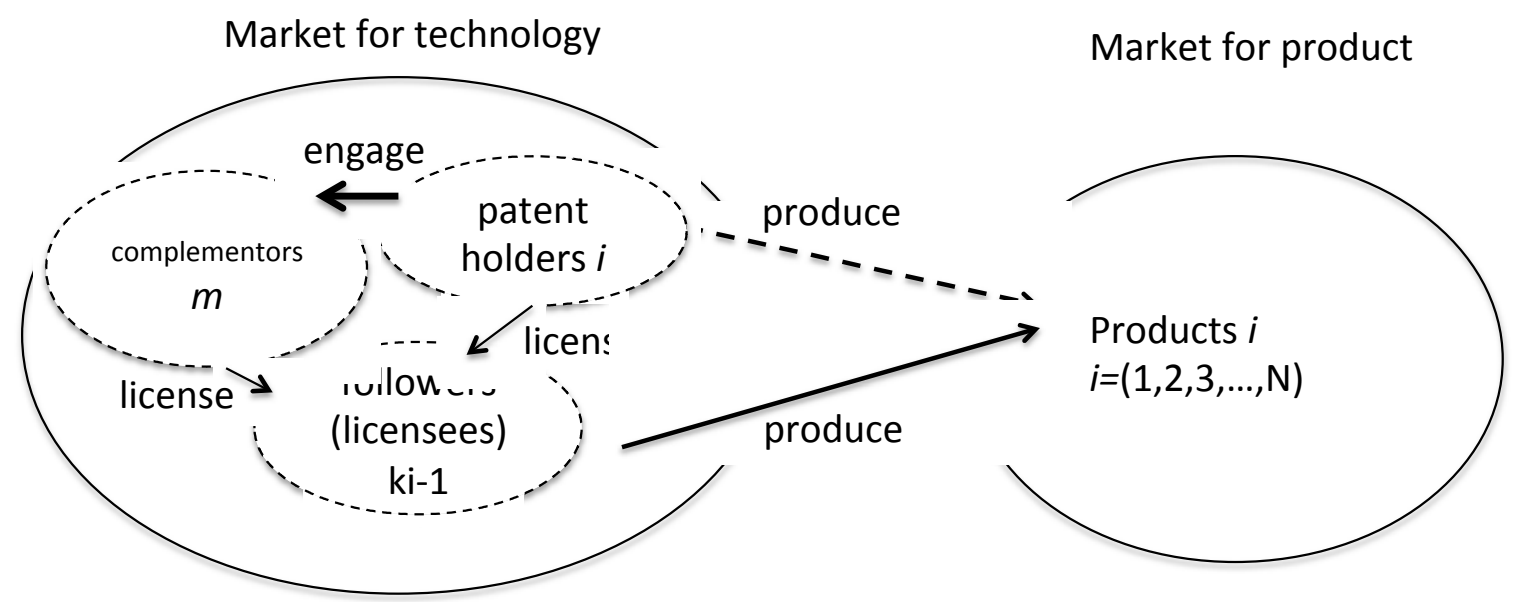

Figure 2. The scenario of the model

Consider a vertically linked market where two stages are involved. The first stage is the market for technology, where technology with patents is main product type and is transferred through licensing contracts. In fact, there are forms other than technology such as know-how and they may flow in other ways. Here we only focus on the licensing activity. Based on Arora and Fosfuri's model (2001), we also assume there are $N$ companies in this market that developed technologies independently and own patents, called technology/patent holders (or innovators). Each of them licenses their technology to a number of licensees (or

followers/new entrants) that have not the necessary developed technologies but possess the capability to manufacture products. Both innovators and new entrants use these technologies to produce goods. We also consider the situation that innovators only license but do not get involved in the product market. Hence we use the dash line to between innovators and the product.

What we add here is the activity of complementors. To study the ecosystem strategy for the patent holder, we assume that patent holder $i$ intentionally engage complementors and partner with them. These complementors therefore license the complementary technologies to firm i's licensees. Thus with more complementary technologies these licensees produce good $i$ of improved quality. One can say that licensees can sign the licensing contracts with complementors themselves. However this may be not always the case. Licensees may fail to do that due to a few reasons. The licensee may not be aware of potential added value of applying the complementary technology into its product. Also, there may be high transaction cost or low bargaining power on the licensee side.

The second stage is the market for product. There are $N$ varieties of goods in the competition. For one of the varieties good $i(i=1,2,3, \ldots, N)$, it is produced with technology $i$ and its related complementary technologies by technology holder $i$ (probably) and its $k_{i}-1$ licensees. These varieties of products can be homogenous or differentiated. Competition in 
this market follows Cournot competition.

Arora and Fosfuri (2003) use two important concepts that describe the effects of licensing impose on the profits of licensors: revenue effect and rent dissipation effect. The revenue effect is positive, which refers to the licensing fees that licensors earn from licensees. The rent dissipation effect indicates the negative effect on profits of licensors due to increased competition in the product market caused by licensees. Arora and Fosfuri (2003) argue that the key to determine firm's licensing strategy is whether the revenue effect dominates the rent dissipation effect. In our model, the two concepts are also important because they help us understand the logic of employing ecosystem strategy. From the following discussion in Findings\&Discussions we can see that ecosystem strategy has a mediating effect on these two effects, and therefore influences firms' profitability.

\section{The analytical model}

Based on the conceptual framework above, in the following we present our mathematical model. Like the conceptual framework, we also base our analytical model on Arora and Fosfuri's (2003). We use the same signs to denote variables. Assume that the number of patent holders is $N$. For one of them, firm $i(i=1,2,3, \ldots, N)$ licenses its technology $i$ to $k_{i}-1$ followers. Since our focus is on the ecosystem strategy, we assume that firm's licensing strategy has reached the optimal level at the equilibrium and will not change in the short term. Hence in our model $k_{i}-1$ is a given number. Hence in the product market there are $k_{i}$ firms producing good $i$, and there are $\sum_{i=1}^{N} k_{i}$ firms in total competing in the product market. As a complementary strategy, firm $i$ engages $m$ complementors and these complementors provide complementary licenses to the $k_{i}-1$ licensees. What we mean by ecosystem strategy in this model is reflected in the value of $m . N, m$ and $k_{i}-1$ are all continuous numbers.

Same as Arora and Fosfuri's model (2003), we assume that the licensing fee is paid through a lump sum payment of a non-exclusive contract. The proportion of licensing payment in the profits earned by licensees is assumed to be $\sigma$.

As Teece (1997) argues, transferring technology involves transaction cost that sources from incomplete contracts, transaction-specific investments and leakages of valuable proprietary information (Teece 1977). We follow the assumption of Arora and Fosfuri (2003) that transaction costs is composed of a fixed $F$ and a variable part that is proportional to the rent generated by the use of the technology. According to Arora and Fosfuri's discussion, we know that this proportion is $1-\sigma$ and is already embodied in the profit that the licensor earn from the total licensing contract.

We assume the degree of product differentiation among goods $i(i=1,2,3, \ldots, N)$ is captured by $\mu \in[0,1]$. When $\mu=1$, all goods are homogenous; when $\mu=0$, all goods are completely differentiated.

In the following we discuss the complementor part. Based on the ecosystem theory, complementors' involvement increases the degree of product differentiation. To make the case simple, we assume this effect to be linear, with $\Delta \mu$ denoting the marginal effect on $\mu$ when involving one more complementor. Hence the degree of product differentiation is $\mu-$ 
$\Delta \mu \cdot m$ when involving $\mathrm{m}$ complementors. In addition, on the technology holder's side, engaging complementors involves transaction cost. We assume this to be fixed cost $\mathrm{F}^{\prime}$.

The analysis process is similar to Arora and Fosfuri's, which is divided into two stages: competition in the product market and competition in the technology market. Here we only briefly outline the process.

Competition in the product market

The inverse demand function for good $i$ is:

$$
p_{i}=1-\sum_{1}^{k_{i}} x_{i}-(\mu-m \Delta \mu) \sum_{j \neq i} \sum_{1}^{k_{j}} x_{j}
$$

where $i=1,2,3, \ldots, N, j=1,2,3, \ldots, N$ and $j \neq i$. $p_{i}$ refers to the price of good $i, x_{i}$ and $x_{j}$ are equilibrium quantities of goods $i$ and $j$ respectively. Hence $\sum_{1}^{k_{i}} x_{i}$ stands for the summation of quantities of good $\mathrm{i}$ supplied by $\mathrm{k}_{\mathrm{i}}$ firms (including the patent holder and its licensees).

From (1) one can solve $\left(p_{i}, x_{i}\right)$ at the equilibrium point and derive the profits $\pi^{i}=p_{i} x_{i}$. Therefore, profits earned by each firm with technology $i$ in the product market is:

$$
\pi^{i}\left(k_{i}, k_{j}, \mu, \Delta \mu, N, m\right)=A^{-2} B^{-2}
$$

where $A=1+(1-\mu+\Delta \mu m) k_{i}$ and $B=1+\sum_{j \neq i}^{N}(\mu-m \Delta \mu) k_{j} /\left(1+(1-\mu+m \Delta \mu) k_{j}\right)$. Competition in the technology market

For technology holder $i$, the total profits earned from its product and licensing is:

$$
V^{i}=\left[1+\sigma\left(k_{i}-1\right)\right] \pi^{i}\left(k_{i}, k_{j}, \mu, \Delta \mu, N, m\right)-\left(k_{i}-1\right) F-m F^{\prime}
$$

where $\left[1+\sigma\left(k_{i}-1\right)\right] \pi^{i}\left(k_{i}, k_{j}, \mu, \Delta \mu, N, m\right)$ refers to the profits earned by its own production and licensing fees, $\left(k_{i}-1\right) F$ refers to the transaction cost with licensees, and $\mathrm{mF}^{\prime}$ stands for the transaction cost with complementors.

We have finished the modification of the basic functions from Arora and Fosfuri's model (2003) under our new framework. We present findings and discussions in the next section. Instead of focusing on number of licensees $k_{i}$, we focus on the influence of complementors and the number of complementors. Thus our discussion will start from $\mu$ and $m$.

\section{FINDINGS \& DISCUSSIONS}

\section{Impact of Engaging Complementors on Profitability}

Before we dive into details, we first examine whether it is profitable to involve complementors. As stated in the theory part, based on previous literature on innovation ecosystems (Adner \& Kapoor 2010, 2015; Adner 2012), we assume that complementors' participation in innovation ecosystems affects the degree of product differentiation in the product market. In other words, the more complementors in the market for technology license their technologies to the same licensees as the focal firm do, the higher degree of product differentiation will be achieved in the market for product.

In this section to make the problem simple, we assume $F^{\prime}=0$ in Expression (3). Hence, one can study the influence of complementor participation by examining the impact of $\mu$ on profit $V^{i}$. Our first proposition is: 
Proposition 1a: in a homogenous product market, where two technology holders license their technologies to the licensees and are also involved in the product market, either firm could increase its profit by engaging $m \in\left[1, \frac{1-\mu_{2}}{\Delta \mu}\right]$ complementors in their licensing deals.

Proof. Assume that now there is no complementor participating. Therefore Expression (2) and (3) can be written as

$$
\begin{gathered}
\pi^{i}\left(k_{i}, k_{j}, \mu, N\right)=\left[1+(1-\mu) k_{i}\right]^{-2}\left[1+\sum_{j \neq i}^{N} \mu k_{j} /\left(1+(1-\mu) k_{j}\right)\right]^{-2} \\
V^{i}=\left[1+\sigma\left(k_{i}-1\right)\right] \pi^{i}\left(k_{i}, k_{j}, \mu, N\right)-\left(k_{i}-1\right) F
\end{gathered}
$$

Now, the inclusion of complementors will add to the product differentiation, which means $\mu$ will decrease when complementary technologies have been licensed to the licensees in the product market. Since we are keen to know to what extent the complementors' participation will affect the profit function of the focal firm, we now work out the first order derivative for $V^{i}$ in terms of $\mu$.

Consider a simple scenario where $N=2$ (we do not consider the scenario of $N=1$ because results from previous literatures suggest that the singletechnology holder should not license their technology), which means the market for technology is duopolistic (two technology holders firm 1 and 2, one can have

$$
\frac{\partial V^{1}}{\partial \mu}=\left[1+\sigma\left(k_{1}-1\right)\right]\left[1+(1-\mu) k_{1}\right]^{-3} \frac{2\left[1+(1-\mu) k_{2}\right]}{\left(1+k_{2}\right)^{2}} \emptyset
$$

where $\varnothing=\mu\left[1+(1-\mu) k_{1}\right]-k_{2}\left[1+(1-\mu) k_{2}\right]$

Now, one can obviously tell $\left[1+\sigma\left(k_{1}-1\right)\right]\left[1+(1-\mu) k_{1}\right]^{-3} \frac{2\left[1+(1-\mu) k_{1}\right]}{\left(1+k_{2}\right)^{2}}>0$. Hence, we are concerned with $\emptyset$ 's monotonicity and one can have

$$
\emptyset=-k_{2} \mu^{2}+\left(1+k_{2}+k_{1} k_{2}\right) \mu-k_{2}\left(1+k_{1}\right)
$$

It is obvious that $\varnothing$ is a parabola open downwards, with roots between $(0,1)$. One can find the roots for $\emptyset$, which are also the roots for $\frac{\partial V^{1}}{\partial \mu}$ :

$$
\begin{aligned}
& \mu_{1}=\frac{1+k_{2}+k_{1} k_{2}-\sqrt{\left(1+k_{2}+k_{1} k_{2}\right)^{2}-4 k_{2}^{2}\left(1+k_{2}\right)}}{2 k_{2}} \\
& \mu_{2}=\frac{1+k_{2}+k_{1} k_{2}+\sqrt{\left(1+k_{2}+k_{1} k_{2}\right)^{2}-4 k_{2}^{2}\left(1+k_{2}\right)}}{2 k_{2}}
\end{aligned}
$$

Hence, when $0<\mu<\mu_{1}$ or $\mu_{2}<\mu<1$, the profit function is decreasing on $\mu$.

This result has two implications. First, when complementors are introduced, $\mu$ starts to decrease from 1 and therefore $V^{1}$ increases, until $\mu_{2}$, where $V^{1}$ reaches the maximum. This implies that, in a homogenous product market, where two firms 1 and 2 license their 
technologies and are also involved in the product market, firm 1 could increase its profit by engaging a reasonable number of complementors in their licensing deals with licensees in the product market. The number of complementors $m$ can be easily derived as

$$
m=\frac{1-\mu_{2}}{\Delta \mu} \in\left[1, \frac{1-\mu_{2}}{\Delta \mu}\right]
$$

where $\Delta \mu$ is the incremental unit per complementor involved. Hence, we have the following proposition.

Proposition 1b: in a homogenous product market, where two technology holders license their technologies to the licensees and also produce the same products in the product market, firm's profit could decrease if the firm engages more than $\frac{1-\mu_{2}}{\Delta \mu}$ complementors in their licensing deals.

Proof. When the degree of product differentiation reaches $\mu_{2}$, technology holder's profit starts to decrease until $\mu_{1}$, and then increase until 0 . In reality, $\mu$ cannot be zero as the two products cannot be completely different even if introducing considerable number of complementors. In fact, even if we assume $\mu=0$, where $V^{1}$ reaches the other possible maximum value $V_{\mu=0}^{1}$

$$
V_{\mu=0}^{1}=\left(1+k_{1}\right)^{-2}\left(1+k_{2}\right)^{-2}\left[1+\sigma\left(k_{i}-1\right)\right]-\left(k_{1}-1\right) F
$$

This value is even smaller than $V_{\mu=1}^{1}$

$$
V_{\mu=1}^{1}=\left(1+k_{2}\right)^{-2}\left[1+\sigma\left(k_{i}-1\right)\right]-\left(k_{1}-1\right) F
$$

Hence, if too many complementors are involved in the licensing deals, the technology holder's profit could decrease and it can even be smaller than the initially homogenous product market.

We suspect that the decrease in profit after $\mu_{2}$ is due to the increase of equilibrium price in the product market is slower than the increase of quantity if too many complementors are introduced. This implies that, for the technology holder, involving too many complementors could decrease the profit. Therefore, one can find that $\mu_{2}$ is the optimal point for technology holders to get the maximum profit through engaging complementors in licensing their technologies.

We now consider the scenario where technology holders are not involved in the product market, i.e. they adopt a license-based business model.

Proposition 1c: in a homogenous product market, where two technology holders only profit from licensing their technologies to the licensees, either firm could increase its profit by engaging $m^{\prime} \in\left[1, \frac{1-\mu_{2}^{\prime}}{\Delta \mu}\right]$ complementors in their licensing deals.

Proof. The profit function for technology holders will then be 


$$
V^{i}=\sigma\left(k_{i}-1\right) \pi^{i}\left(k_{i}-1, k_{j}-1, \mu, N\right)-\left(k_{i}-1\right) F
$$

A close examination will easily prove that the result in the last section still holds in this scenario. In other words, if the technology holder is purely profiting from licensing their technologies, engaging complementors in an originally homogenous product market will increase their profit. The new optimal point $\mu_{2}^{\prime}$ and number of complementors $m^{\prime}$ will be

$$
\begin{gathered}
\mu_{2}^{\prime}=\frac{k_{2}+\left(k_{1}-1\right)\left(k_{2}-1\right)+\sqrt{\left[k_{2}+\left(k_{1}-1\right)\left(k_{2}-1\right)\right]^{2}-4 k_{2}\left(k_{2}-1\right)^{2}}}{2\left(k_{2}-1\right)} \\
m^{\prime}=\frac{1-\mu_{2}^{\prime}}{\Delta \mu} \in\left[1, \frac{1-\mu_{2}^{\prime}}{\Delta \mu}\right]
\end{gathered}
$$

The above results have strong practical implications: if we ignore the licensing asymmetry (the relative value of $k_{1}$ and $k_{2}$ ), engaging a certain number of complementors and nurturing ecosystems will benefit the technology holders regardless of their business model either licensing only or licensing plus manufacturing their own products.

An excellent example would be ARM. The microprocessor industry, where ARM finds itself, is highly disintegrated and was fragmented. Initially, there are multiple technology holders including ARM and Intel in this industry. The business models of these holders are different. For example, Intel manufactures their own processors besides licensing. ARM, however, has adopted a pure license-based business model since the beginning - it only profits from licensing the ARM architectures to microprocessor OEMs who will design and manufacture the processors using ARM's technology. These processors will then be embedded by mobile device OEMs in smartphones and tablets. In other words, ARM does not involve in the product market and only focuses on the market for technology.

The reason why ARM could stand out has largely been attributed to their ecosystem strategy (Garnsey et al. 2008; Rong et al. 2015; Liu \& Rong 2015). It was found that there were difficulties for some processor OEMs, especially those smaller ones, to successfully design their products with ARM's architectures alone, in which case some complementary technologies need to be used such as EDA (Electronic Design Automation). ARM has proactively approached and collaborated with some of these complementors, who can help processor OEMs to design their system on chips ( $\mathrm{SoC})$. This ecosystem strategy has greatly expanded ARM's market and increased its profit. By now, ARM has become one of the two giants (the other is Intel) in microprocessor industry and particularly dominated the mobile device microprocessor market for technology.

In the following part we link ecosystem strategy with firms' existing licensing strategy, and see how the licensing scenario impacts licensors' ecosystem strategy. We consider a more complete situation with transaction cost of engaging complementors $F^{\prime}>0$. .

\section{Engaging complementors and the asymmetry of the licensing scenario}

Now we consider the effect of asymmetry in the licensing market on firm's ecosystem strategy. Let $F^{\prime}>0$, and therefore profit of the patent holder is given by Expression (3). 
We consider the situation that before involving their complementors, now $N$ technology holders have reached the equilibrium in terms of licensing strategy. This means for technology holder $i(\mathrm{i}=1,2,3, \ldots, N), k_{i}$ and $k_{j}$ are given numbers. Now technology holder $i$ is considering whether to involve complementors to increase the profitability and how many they should involve. Therefore we discuss the derivative of $V^{i}$ with respect to $m$.

$$
V_{m}^{i}=\left[1+\sigma\left(k_{i}-1\right)\right] \pi_{m}^{i}-F^{\prime}
$$

where $\pi_{m}^{i}=\frac{d\left(A^{-2} B^{-2}\right)}{d m}=-2 A^{-2} B^{-2}\left(A^{-1} \frac{d A}{d m}+B^{-1} \frac{d B}{d m}\right)$. One can derive that $\frac{d A}{d m}=\Delta \mu k_{i}$ and $\frac{d B}{d m}=\sum_{j \neq i}^{N} \frac{k_{j} \Delta \mu\left(k_{j}+1\right)}{\left(k_{j} \Delta \mu m+1\right)^{2}}$. It can be seen that the expression of $V_{m}^{i}$ is very complicated especially for $\frac{d B}{d m}$. To simplify the scenario, now we consider the case where $N=2$, which means there are two patent holders named 1 and 2 (duopoly) in the technology market. Firm 1 licenses its technology 1 to $k_{1}-1$ firms, and firm 2 licenses its technology 2 to $k_{2}-1$ firms. Assume $\mu=1$, which means all firms produce the homogenous good at the beginning. Since we consider the case where complementors have not been engaged, we let the initial value of $m$, $m_{0}=0$. Under this circumstance, we derive that for firm 1 the derivative of total profit $V^{1}$ with respect to $m$ is

$$
V_{m}^{1}=\left[1+\sigma\left(k_{1}-1\right)\right] \pi_{m}^{1}-F^{\prime}=-2 \frac{\left[1+\sigma\left(k_{1}-1\right)\right]}{\left(1+k_{2}\right)^{2}} \cdot \frac{\left(\Delta \mu k_{2} m+1\right)^{2}}{\left(\Delta \mu k_{1} m+1\right)^{2}}\left(\frac{\Delta \mu k_{1}}{\Delta \mu k_{1} m+1}-\frac{\Delta \mu k_{2}}{\Delta \mu k_{2} m+1}\right)-F^{\prime}
$$

We now discuss the value of $V_{m}^{1}$ that indicates the change of firm 1's profitability with the number of complementors $m$ and further discuss when to engage complementors for firm 1 in the given licensing scenario. The following are the description of the scenario and two related propositions.

Scenario: In a technology market, two patent holders exist and license their own technologies to other firms. The licensing market has reached the equilibrium. The two firms are also both involved in the product market. Goods of the two varieties are homogenous at the beginning.

Proposition 2a. For one of the patent holders it can consider engaging complementors when two conditions are satisfied: the firm licenses its technology to fewer firms than the other; the transaction cost with complementors is small.

Proof. We adopt firm 1's stance. We have solved the expression of $V_{m}^{1}$, seen as Expression (14). In (14), we can see that $-2 \frac{\left[1+\sigma\left(k_{1}-1\right)\right]}{\left(1+k_{2}\right)^{2}} \cdot \frac{\left(\Delta \mu k_{2} m+1\right)^{2}}{\left(\Delta \mu k_{1} m+1\right)^{2}}$ is always negative. In addition,

function $f(k)=\frac{\Delta \mu k}{\Delta \mu k m+1}$ increases in $k$ monotonically. Hence, when $k_{1}$ is larger than $k_{2}$ and $F^{\prime}$ is small, $V_{m}^{1}$ may be positive. Under the circumstances, involving complementors brings more benefit to firm 1 . Especially if $F^{\prime}=0$, which means firm 1 has very easy access to its 
complementors, it is always profitable to engage complementors as long as $k_{1}<k_{2}$ regardless the value of $\sigma$ and $\Delta \mu$.

It is difficult to solve $V_{m}^{1}=0$ and find the analytical solution of $m$ at the equilibrium because it is a third degree polynomial equation. Also, one does not have to do so in the practice. Under a specific circumstance, we can solve the equilibrium $m$ with estimations of $k_{1}, k_{2}, \Delta \mu, \sigma$ using numerical analysis. Let us consider a completely imaginary but typical scenario where $k_{1}=6, k_{2}=12, \Delta \mu=0.01, \sigma=0.8$. Let $V_{m}^{1}=0$, the equation can be written as

$$
\frac{0.05(0.12 m+1)}{11(0.06 m+1)^{3}}=F^{\prime}
$$

It can be seen that with a small value of $F^{\prime}, m$ can be positive. In addition, the left side of (15) is decreasing with $m$. Hence, in this specific scenario, the firm should involve complementors when the transaction cost is small, and should involve more when $F^{\prime}$ is smaller.

The result indicates that relative number of licensees of incumbents is the key to determine their ecosystem strategy in the licensing behaviour. Involving complementors can be beneficial when the firm is licensing less aggressively than its competitor in the technology market. This can also be explained in the intuitive logic. For firms 1 and 2 in a technology market with firm 2 licensing to more followers, licensees of firm 2 are causing more rent dissipation effect due to greatly increased competition in the product market. This negative effect is shared across firm 1 and 2 because good 1 and 2 are completely homogenous, while only firm 2 benefit from licensing fees of these licensees. As a result, firm 1 undertakes more rent dissipation effect because $k_{2}-1$ is larger. Now if firm 1 engages complementors and encourages them to license complementary products to its licensees, good 1 becomes differentiated from good 2 in the product market. Market for the two goods is separated into two niche markets (Arora \& Fosfuri 2003), and competition becomes more close in each one. Two positive effects happen on firm 1: with less market share for good 1 at the beginning, now its market share increases as a result of product differentiation and profit for firm 1 increases; the rent dissipation effect caused by firm 2's licensees is reduced on firm 1 because good 2 itself becomes a more close competitive market.

Still in this scenario, now we discuss for the firm that is licensing more, what should it do in terms of the ecosystem strategy.

Proposition $\mathbf{2 b}$. For one of the patent holders, if it licenses its technology to more firms than the other, it is not favorable to involve complementors into the technology market.

Proof. Following the proof of proposition 2a, we can see that in Expression (14), if $k_{1}>k_{2}$, then $\frac{\Delta \mu k_{1}}{\Delta \mu k_{1} m+1}-\frac{\Delta \mu k_{2}}{\Delta \mu k_{2} m+1}>0$ and $V_{m}^{1}$ will be always negative whatever the value of $m$ is. In this case, profit will always decrease no matter how many complementors are involved.

The result implies that involving complementors is not always beneficial. The logic is similar to that in Proposition 2a. If firm 1 licensing more aggressively than firm 2, firm 2 undertakes more rent dissipation effect caused by firm 1's larger number of licensees. Now if firm 1 
engages complementors and builds its innovation ecosystem, good 1 is improved and differentiated from good 2. Although this increased degree of differentiation leads to the increasing market share of good 1 in the competition, the larger rent dissipation effect caused by $k_{1}-1$ licensees is undertaken more by firm 1 because of closer competition. Hence, overall for firm 1 the rent dissipation effect dominates the revenue effect under this circumstance.

Proposition $2 \mathrm{a}$ and $2 \mathrm{~b}$ together present an interesting insight that the asymmetry in $\mathrm{a}$ licensing equilibrium is the key to determine firms' ecosystem strategy. This provides practical implications for firms in the inferior position in the licensing competition. They can compete with the dominant licensor by employing ecosystem strategy as a complementary strategy. Literature has shown that licensing competition is not rare among many firms (Arora 1997). However, adoption of other supportive strategy has been ignored by firms in the competition. This result indicates additional strategic space for the 'weaker licensor', or in other words, shows that the asymmetric position in the licensing competition generates a strategic incentive for involving complementors.

Note that this result is based on the scenario that licensors are also involved in the product market, which may apply to many large firms. As stated in the introduction part, in addition to start-ups that do not possess the capability to manufacture, large firms also license actively. Hence these two propositions are more related to those that also participate in the product competition. For the licensor that earn profits only through licensing, this does not apply because the rent dissipation effect due to licensees' competition does not exist.

\section{CONCLUSION}

Licensing has been a common instrument for firms to exploit or acquire technologies. In addition to this purpose, firms also license their technologies out for strategic use. Although literature has discussed the optimal licensing strategy, this does not mean firms can fully exploit the value from their technologies by licensing. They still face the erosion of the patents' value sourcing from other challenges. One challenge is posed by the presence of innovation ecosystem, where complementors have great impact on both licensors' and licensees' product performance. This on the other hand offers the strategic space for licensors to exploit more rent from their technologies. Therefore, licensors need to adopt proper ecosystem strategy to support its licensing strategy and hence increase overall profits.

By extending the licensing model from the literature and adding the involvement of complementors our paper shows that the participation of complementors brings more profit to licensors. However, our analysis also shows that the profitability of licensors is a non-linear $U$-shaped function with the number of complementors engaged. When licensors involve too many complementors, the equilibrium of product competition will move beyond the optimal status and reduce the licensors' overall profits. The result also applies to licensors that are not engaged in the product market.

Another important result of our analysis is that technology holders' ecosystem strategy is greatly influenced by the asymmetry of the licensing competition. In reality, the extent of 
licensing across firms in the technology market is usually different. We show that in a technology market where two patent holders exist and are asymmetric in licensing, if one of the firms licenses less aggressively, it should engage a certain number of complementors as a complementary strategy to improve profitability. However, if one of the firms is a dominant licensor, it should not involve complementors. In this case ecosystem strategy would conflict with the licensing strategy. We also provide tentative explanation for the result, which also contains insights on the relationship between ecosystem and licensing.

One limitation of our model is that we treat the licensing strategy as static rather than a dynamic strategy. This means numbers of licensees are fixed in our analysis. This makes sense in the short term. However in the long run, since involvement of complementors will impact the product competition, according to Arora and Fosfuri (2003), other firms will adjust their number of licensees to deal with the new situation in the product market. Hence, if our model is seen as a binary function with two variables $k_{i}$ and $m$, one can find the equilibrium for optimal both licensing strategy and ecosystem strategy. Therefore the alignment of these two strategies can be discussed, which will be an interesting topic for future research. 


\section{REFERENCES}

Adner, R., 2016. Ecosystem as Structure: An Actionable Construct for Strategy. Journal of Management, $\mathrm{XX}(\mathrm{X})$, pp.1-20. Available at:

http://jom.sagepub.com/cgi/doi/10.1177/0149206316678451.

Adner, R., 2017. Ecosystem as Structure: An Actionable Construct for Strategy. Journal of Management, 43(1), pp.39-58.

Adner, R., 2006. Match your innovation strategy to your innovation ecosystem. Harvard business review, 84(4), p.98.

Adner, R., 2012. The wide lens: A new strategy for innovation, Penguin UK.

Adner, R. \& Kapoor, R., 2015. Innovation ecosystems and the pace of substitution: re-examining technology s-curves. Strategic Management Journal.

Adner, R. \& Kapoor, R., 2010. Value creation in innovation ecosystems: how the structure of technological interdependence affects firm performance in new technology generations. Strategic Management Journal, 31(2), pp.306-333.

Alexy, O., Criscuolo, P. \& Salter, A., 2009. Does IP strategy have to cripple open innovation? MIT Sloan Management Review, 51(1), pp.71-77. Available at: http://search. proquest.com.library.capella.edu/docview/224960458?accountid=27965.

Allarakhia, M. \& Walsh, S., 2011. Managing knowledge assets under conditions of radical change: The case of the pharmaceutical industry. Technovation, 31(2-3), pp.105-117. Available at: http://dx.doi.org/10.1016/j.technovation.2010.11.001.

Arora, A., 1997. Patents, licensing, and market structure in the chemical industry. Research Policy, 26, pp.391-403.

Arora, A. \& Ceccagnoli, M., 2006. Patent Protection, Complementary Assets, and Firms' Incentives for Technology Licensing. Management Science, 52(2), pp.293-308.

Arora, A. \& Fosfuri, A., 2003. Licensing the market for technology. Journal of Economic Behavior \& Organization, 52(2), pp.277-295. Available at:

http://linkinghub.elsevier.com/retrieve/pii/S0167268103000027.

Arora, A., Fosfuri, A. \& Gambardella, A., 2001. Markets for Technology and their Implications for Corporate Strategy. Industrial and Corporate Change, 10(2), pp.419-451. Available at: http://icc.oupjournals.org/cgi/doi/10.1093/icc/10.2.419.

Autio, E. \& Thomas, L.D.W., 2016. Tilting the Playing Field: Towards an Endogenous Strategic Action Theory of Ecosystem Creation. Academy of Management Proceedings, 2016(1), p.11264.

Bonanno, G. \& Vickers, J., 1988. Vertical Separation. The Journal of Industrial Economics, 36(3), pp.257-265.

Caves, R.E., Crookell, H. \& Killing, J.P., 1983. The Imperfect Market for Technology Licenses. Oxford Bulletin of Economics and Statistics, 45(3), pp.249-267.

Cohen, B., 2006. Sustainable valley entrepreneurial ecosystems. Business Strategy and the Environment, 15(1), pp.1-14.

Davis, J.P., 2016. The Group Dynamics of Interorganizational Relationships: Collaborating 
with Multiple Partners in Innovation Ecosystems. Administrative Science Quarterly, pp.141.

Gallini, N.T., 1984. Deterrence by Market Sharing: A Strategic Incentive for Licensing. The American Economic Review, 74(5), pp.931-941.

Gallini, N.T., 1992. Patent Policy and Costly Imitation. The RAND Journal of Economics, 23(1), pp.52-63. Available at:

http://search.ebscohost.com/login.aspx?direct=true \&db=buh\&AN=5189348\&site=ehostlive.

Gallini, N.T. \& Wright, B.D., 1990. Technology Transfer under Asymmetric Information. RAND journal of economics, 21(1), pp.147-160.

Garnsey, E., Lorenzoni, G. \& Ferriani, S., 2008. Speciation through entrepreneurial spin-off: The Acorn-ARM story. Research Policy, 37(2), pp.210-224.

Gawer, A. \& Cusumano, M.A., 2013. Industry Platforms and Ecosystem Innovation. Journal of Product Innovation Management, 31(3), pp.417-433.

Grindley, P.C. \& Teece, D.J., 1997. Managing intellectual capital: licensing and cross-licensing in semiconductors and electronics. California Management Review, 39(2), pp.8-41. Available at:

http://ieeexplore.ieee.org/xpls/abs_all.jsp?arnumber=692195.

Hadfield, G.K., 1991. Credible Spatial Preemption through Franchising. RAND journal of economics, 22(4), pp.531-543.

lansiti, M. \& Levien, R., 2004a. Keystones and dominators: framing operating and technology strategy in a business ecosystem. Harvard Business School, Working Paper, pp.3-61. Available at: http://www.libraryservices.nl/jip/sites/default/files/Ecosystems.pdf [Accessed May 7, 2014].

lansiti, M. \& Levien, R., 2004b. Strategy as Ecology. Harvard Business Review, 82.

lansiti, M. \& Richards, G., 2006. Information Technology Ecosystem: Structure, Health, and Performance. Antitrust Bull. Available at:

http://heinonlinebackup.com/hol-cgi-bin/get_pdf.cgi?handle=hein.journals/antibull51\&se ction=10 [Accessed May 5, 2014].

Kamiyama, S., Sheehan, J. \& Martinez, C., 2006. Valuation and Exploitation of Intellectual Property. OECD Science, Technology and Industry Working Papers, 2006/05, p.48. Available at: http://dx.doi.org/10.1787/307034817055.

Kapoor, R. \& Lee, J., 2013. Coordinating and competing in ecosystems: How organizational forms shape new technology investments. Strategic Management Journal, 296(July 2012), pp.274-296.

Katz, M.L. \& Shapiro, C., 1986. Technology Adoption in the Presence of Network Externalities. Journal of political economy, 94(4), pp.822-841.

Lichtenthaler, U., 2005. External commercialization of knowledge: Review and research agenda. International Journal of Management Reviews, 7(4), pp.231-255.

Liu, G. \& Rong, K., 2015. The Nature of the Co-Evolutionary Process: Complex Product Development in the Mobile Computing Industry's Business Ecosystem. Group \& Organization Management, 40(6), pp.809-842. 
Moore, J.F., 2004. Business ecosystems and the view from the firm. Antitrust Bull., 51, pp.3175.

Moore, J.F., 1993. Predators and prey: a new ecology of competition. Harvard business review, 71(3), pp.75-86.

Moore, J.F., 1996. The Death of Competition: Leadership and Strategy in the Age of Business Ecosystems,

Nambisan, S. \& Baron, R.A., 2013. Entrepreneurship in Innovation Ecosystems:

Entrepreneurs' Self-Regulatory Processes and Their Implications for New Venture Success. Entrepreneurship Theory and Practice, 37(5), pp.1071-1097.

Rivette, K.G. \& Kline, D., 2000. Rembrandts in the attic: Unlocking the hidden value of patents, Harvard Business Press.

Rockett, K.E., 1990. Choosing the Competition and Patent Licensing. The RAND Journal of Economics, 21(1), pp.161-171.

Rong, K. et al., 2015. Nurturing business ecosystems for growth in a foreign market: Incubating, identifying and integrating stakeholders. Journal of International Management, 21(4), pp.293-308.

Rong, K. \& Shi, Y., 2014. Business Ecosystems Constructs, Configurations, and the Nurturing Process, Springer.

Shepard, A., 1987. Licensing to Enhance Demand for New Technologies. The RAND Journal of Economics, 18(3), pp.360-368.

Teece, D.J., 1998. Capturing value from knowledge assets: The new economy, markets for know-how, and intangible assets. California Management Review, 40(3), pp.55-80.

Teece, D.J., 1986. Profiting from technological innovation : Implications for integration , collaboration, licensing and public policy. Research Policy, 15(February), pp.285-305.

Teece, D.J., 1977. Technology Transfer by Multinational Firms : The Resource Cost of Transferring Technological Know-How. The Economic Journal, 87(346), pp.242-261.

Thomas, L.D.W. \& Autio, E., 2015. The processes of ecosystem emergence. Academy of Management Proceedings, 2015(1), pp.10453-10453.

Vickers, J., 1985. Delegation and the Theory of the Firm. The economic journal, 95(1985), pp.138-147. 